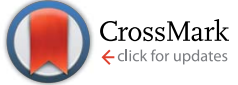

Cite this: RSC Adv., 2014, 4, 30617
Received 24th March 2014 Accepted 20th June 2014

DOI: $10.1039 / c 4 r a 02551 b$

www.rsc.org/advances

\section{Halogen-free pyrrolidinium bis(mandelato)borate ionic liquids: some physicochemical properties and lubrication performance as additives to polyethylene glycol†}

\author{
Mamoun Taher, ${ }^{a}$ Faiz Ullah Shah, ${ }^{a}$ Andrei Filippov, ${ }^{\text {ab }}$ Patrick de Baets, ${ }^{c}$ \\ Sergei Glavatskin ${ }^{\star c d}$ and Oleg N. Antzutkin ${ }^{\star a e}$
}

\begin{abstract}
This work reports on the synthesis and physicochemical characterisation of novel halogen-free boron containing ionic liquids (hf-BILs) with dialkylpyrrolidinium cations $\left[\mathrm{C}_{n} \mathrm{C}_{1} \text { Pyrr }\right]^{+}, n=4-14$, and bis(mandelato)borate anion $[\mathrm{BMB}]^{-}$. All the synthesised compounds are liquids at room temperature. It was found that the thermal properties and density of these hf-BILs are affected by the length of the longest alkyl chain connected to the nitrogen atom in the pyrrolidinium cations. Differential scanning calorimetry measurements revealed that glass transition temperatures of these ionic liquids are in the temperature range from 218 to $241 \mathrm{~K}$. Interestingly, the glass transition temperatures follow the "oddeven" effect related to the number of carbons $(n)$ in one of the alkyl chains of $\left[C_{n} C_{1} \text { Pyrr }\right]^{+}$. It was also found that hf-BILs' density decreases with an increase in the alkyl chain length of $\left[\mathrm{C}_{n} \mathrm{C}_{1} \text { Pyrr }\right]^{+}$. It is suggested that the "odd-even" effect is associated with the difference in packing and specific interactions of cations and anions of this class of hf-BILs. Their lubricating properties, as $3 \mathrm{wt} \%$ additives in polyethylene glycol (PEG), were evaluated in steel-steel contacts. PEG with hf-BILs additive provided significantly lower wear and friction compared to the neat PEG and 5 W40 engine oil. It was found that shortening the length of the longest alkyl chain in the cations of $\left[C_{n} C_{1}\right.$ Pyrr][BMB] significantly reduces frictional losses. Antiwear properties of $\left[C_{n} C_{1}\right.$ Pyrr] $[B M B]$ in $P E G$ follow the same trend.
\end{abstract}

\section{Introduction}

In all industrial applications, there is a rapidly growing trend towards increased machine service life, durability, reduced emissions and minimized energy consumption. ${ }^{1}$ A considerable amount of energy is wasted to overcome friction in different machines and mechanisms. In addition, wear of their components negatively affects functionality and ultimately forces their replacement leading to substantial economic losses. ${ }^{2}$ Availability of the efficient lubrication technology is the key condition to meet the challenges.

Consequently, considerable research efforts have being made to develop novel lubrication technologies and formulate

${ }^{a}$ Chemistry of Interfaces, Luleå University of Technology, SE-97187, Luleå, Sweden ${ }^{b}$ Kazan Federal University, 420008 Kazan, Russian Federation

'Department of Mechanical Construction and Production, Ghent University, B-9000 Ghent, Belgium

${ }^{d}$ System and Component Design, KTH Royal Institute of Technology, SE-10044 Stockholm, Sweden

${ }^{e}$ Department of Physics, University of Warwick, CV4 7AL, Coventry, UK. E-mail: segla@ kth.se; olan@ltu.se

$\dagger$ Electronic supplementary information (ESI) available. See DOI: 10.1039/c4ra02551b. lubricants capable to deliver required performance. ${ }^{3}$ Ionic liquids (ILs) are attractive candidates to be used as the next generation of lubricants or additives to lubricant due to their unique properties. ILs are salts composed of cations and anions, which are liquids below $100^{\circ} \mathrm{C}$. A great body of research work done on ILs have demonstrated their promising functions as new materials for an extensive number of applications. ${ }^{4}$ Many ILs have negligible vapour pressure, ${ }^{5}$ are non-flammable ${ }^{6}$ possess attractive electrochemical properties, ${ }^{7}$ high conductivities ${ }^{8}$ high affinities to metal ions, ${ }^{9}$ high thermal stabilities, ${ }^{10}$ and in particular provide outstanding tribological performance as neat lubricants and as additives to lubricants. ${ }^{\mathbf{1 1 , 1 2}}$

The physiochemical properties of ILs are affected by the selective combination of cations and anions. Designability of ILs makes them attractive candidates for a wide range of

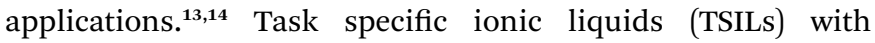
designed physicochemical characteristics are a hot topic in the field of ILs research. TSILs are mainly designed by incorporation of various functional groups into cations, although a few examples involving functionalised anions are also known. ${ }^{\mathbf{1 4}}$ After the original work of Rogers and coworkers, ${ }^{6}$ TSILs' applications in electrochemistry, ${ }^{7}$ catalysis, ${ }^{7}$ synthesis, ${ }^{15}$ separation analysis, ${ }^{16}$ lubrication, ${ }^{\mathbf{1}, 17}$ and functional materials ${ }^{\mathbf{1 8}}$ have been 
demonstrated. However, the fundamental understanding of the relationship between TSILs' molecular structure and their physicochemical properties has not yet been achieved. ${ }^{\mathbf{1 9}}$

Halogen-based ILs are the most commonly studied compounds that are also considered for different applications. However, most of halogen based ILs are sensitive to moisture and may hydrolyse in the presence of water giving rise to hydrogen fluoride (HF) among other corrosive products. The hydrolytic products may ultimately damage the system in which these ILs are intended to be used. Therefore, functional and environmental regulations place restrictions on halogen containing ILs. ${ }^{20}$ Consequently, there is a strong drive towards the development of halogen-free ILs.,

Chelated orthoborate anions may form ILs when combined with different cations. $^{3,21-23}$ However, chelated orthoborate based ILs have significantly higher viscosities compared to ILs with the same cations but halogen-containing anions. ${ }^{22,24}$ Such ILs can be used as efficient additives to lubricating oils.

We have recently reported on the novel classes of halogenfree (hf) chelated orthoborate ILs (hf-BILs) with outstanding tribochemical properties. hf-BILs with tetraalkylphosphonium cations exhibited significantly better antiwear and friction reducing performance in boundary lubrication of the steelaluminium contacts compared to $15 \mathrm{~W} 40$ engine oil., ${ }^{1,3}$ Other potential applications, for example, cholinium bis(salicylato) borate, can be used for extraction of lanthanum ions from aqueous solutions. ${ }^{21}$

The objective of this work is to further explore properties of novel hf-BILs. This time we focus on orthoborate based hf-BILs with pyrrolidinium cations. hf-BILs composed of the bis(mandelato)borate anion $[\mathrm{BMB}]^{-}$and pyrrolidinium $\left[\mathrm{C}_{n} \mathrm{C}_{1} \mathrm{Pyrr}\right]^{+}$ cations with alkyl groups of different chain length, $n=4-14$, were synthesised. Their physicochemical and tribological properties were studied using a range of experimental techniques.

\section{Experimental}

\subsection{Chemicals}

Boric acid (Merck, 99.8\% purity), sodium hydroxide (Merck, 99\% purity), mandelic acid (Aldrich, 99\% purity), $N$-methylpyrrolidine (Fluka, $>99 \%$ purity), 1-chlorobutane (Sigma Aldrich, $>99 \%$ purity), 1-bromopentane (Aldrich, $>99 \%$ purity), 1-bromohexane (Aldrich, $>98 \%$ purity), 1-bromoheptane (Aldrich, >99\% purity), 1-chlorooctane (Aldrich, >99\% purity), 1bromodecane (Aldrich, $>98 \%$ purity), 1-chlorododecane (Aldrich, $>97 \%$ purity), 1-bromotetradecane (Aldrich, >97\% purity), dichloromethane (Fluka, $>99.7 \%$ purity), toluene (Fluka, $>99.7 \%$ purity), diethyl ether (Sigma Aldrich, $>99 \%$ purity) were used as received.

\subsection{Synthesis}

hf-BILs were synthesised using a slightly modified method reported previously. ${ }^{22,23}$ As an example, the synthesis and the chemical characterisation of $N$-butyl- $N$-methylpyrrolidinium bis(mandelato)borate, $\left[\mathrm{C}_{4} \mathrm{C}_{1} \mathrm{Pyrr}\right][\mathrm{BMB}]$, is given below, while the synthetic procedures and characterisation details including yields, liquid state ${ }^{1} \mathrm{H},{ }^{13} \mathrm{C}$ and ${ }^{11} \mathrm{~B}$ NMR data for all other hfBILs are included in the ESI. $\dagger$

2.2.1 Synthesis of $\mathrm{N}$-butyl- $\mathrm{N}$-methylpyrrolidinium bis(mandelato)borate, $\left[\mathrm{C}_{\mathbf{4}} \mathrm{C}_{\mathbf{1}}\right.$ Pyrr $][\mathrm{BMB}]$

Step 1. $N$-Butyl- $N$-methylpyrrolidinium chloride was prepared by admixing 1-chlorobutane $(9.26 \mathrm{~g}, 100 \mathrm{mmol})$ dropwise to a flask with $N$-methylpyrrolidine $(8.51 \mathrm{~g}, 100 \mathrm{mmol})$ dissolved in $15 \mathrm{~mL}$ toluene. The reaction mixture was refluxed for 24 hours under nitrogen atmosphere at $388 \mathrm{~K}$. Toluene was rotary evaporated and a white powder of $N$-butyl- $N$-methylpyrrolidinium chloride was obtained in $86 \%$ yield.

Step 2. Sodium bis(mandelato)borate was prepared by adding mandelic acid $(15.21 \mathrm{~g}, 100 \mathrm{mmol})$ to an aqueous solution of sodium carbonate $(2.65 \mathrm{~g}, 25 \mathrm{mmol})$ and boric acid $(3.09 \mathrm{~g}$, $50 \mathrm{mmol}$ ) dissolved in $100 \mathrm{~mL}$ distilled water. The solution was stirred for two hours at $333 \mathrm{~K}$. The reaction mixture was cooled to room temperature and $(8.88 \mathrm{~g}, 50 \mathrm{mmol})$ of $N$-butyl- $N$ methylpyrrolidinium chloride was added. An organic layer formed during stirring for 3 hours at room temperature was extracted with $100 \mathrm{~mL}$ of $\mathrm{CH}_{2} \mathrm{Cl}_{2}$. The organic layer was washed three times with distilled water to remove traces of sodium chloride. The $\mathrm{CH}_{2} \mathrm{Cl}_{2}$ was rotary evaporated under reduced pressure. A viscous colourless IL, $N$-butyl- $N$-methylpyrrolidinium bis(mandelato)borate, $\left[\mathrm{C}_{4} \mathrm{C}_{1} \mathrm{Pyrr}\right][\mathrm{BMB}]$, was obtained in $71 \%$ yield (32.2 g). Before characterisation and tribotests, $\left[\mathrm{C}_{4} \mathrm{C}_{1}\right.$ Pyrr $][\mathrm{BMB}]$ and other synthesised hf-BILs were dried under vacuum $\left(<10^{-3}\right.$ mbar $)$ during 5 hours at $343 \mathrm{~K}$.

Anal. calcd for $\mathrm{C}_{25} \mathrm{H}_{32} \mathrm{O}_{6} \mathrm{BN}$ ( $\mathrm{MW} 453.33 \mathrm{~g} \mathrm{~mol}^{-1}$ ) C, 66.23; $\mathrm{H}$, 7.11; N, 3.09. Found: C, 63.45; H, 7.2; N, 3.4. Only insignificant impurities were detected in $\left[\mathrm{C}_{4} \mathrm{C}_{1} \mathrm{Pyrr}\right][\mathrm{BMB}]$ by ${ }^{13} \mathrm{C} \mathrm{NMR}$, see Fig. SI-2. $\dagger$

Water content: $0.082 \pm 0.002 \mathrm{wt} \%$. Chlorine content: 0.0291 wt\%. Sodium content: 0.0198 wt $\%$.

${ }^{1} \mathrm{H}$ NMR (359.92 MHz, $\mathrm{CDCl}_{3}$ ): 7.62-7.53 (m, 4H, $\left.\mathrm{C}_{6} \mathrm{H}_{5}\right), 7.33-$ $7.27\left(\mathrm{~m}, 4 \mathrm{H}, \mathrm{C}_{6} H_{5}\right), 7.26-7.22\left(\mathrm{~m}, 2 \mathrm{H}, \mathrm{C}_{6} H_{5}\right), 5.27\left(\mathrm{~d}, 1 \mathrm{H},{ }^{4} J_{H H}=\right.$ $\left.1.2 \mathrm{~Hz}, \mathrm{C}_{6} \mathrm{H}_{5}-\mathrm{CH}\right), 5.23\left(\mathrm{~d}, 1 \mathrm{H},{ }^{4} J_{H H}=3.3 \mathrm{~Hz}, \mathrm{C}_{6} \mathrm{H}_{5}-\mathrm{CH}\right), 3.03-$ $2.96\left(\mathrm{~m}, 4 \mathrm{H}, \mathrm{N}-\left(\mathrm{CH}_{2}-\mathrm{CH}_{2}-\right)_{2}\right.$ pyrrolidinium ring), 2.98-2.83 (m, $2 \mathrm{H}, \mathrm{N}-\mathrm{CH}_{2}-\mathrm{CH}_{2}-$, alkyl chain), $2.52\left(\mathrm{~s}, 3 \mathrm{H}, \mathrm{N}-\mathrm{CH}_{3}\right), 1.83-1.76$ (m, $4 \mathrm{H}, \mathrm{N}-\left(\mathrm{CH}_{2}-\mathrm{CH}_{2}\right)_{2}$, pyrrolidinium ring), $1.39-1.31(\mathrm{~m}, 2 \mathrm{H}$, $\mathrm{N}-\mathrm{CH}_{2}-\mathrm{CH}_{2}-\mathrm{CH}_{2}-$, alkyl chain), $1.30-1.07$ (m, 2H, N- $\mathrm{CH}_{2}-\mathrm{CH}_{2}-$ $\mathrm{CH}_{2}-$, alkyl chain), $0.82\left(\mathrm{t}, 3 \mathrm{H},{ }^{3} \mathrm{~J}_{\mathrm{HH}}=7.5 \mathrm{~Hz},-\mathrm{CH}_{2}-\mathrm{CH}_{3}\right) \mathrm{ppm}$.

${ }^{13} \mathrm{C} \mathrm{NMR}\left(90.506 \mathrm{MHz} \mathrm{CDCl}_{3}\right): 177.90$ (s, 2C, $\left.>C=\mathrm{O}\right), 139.90$ (s, 2C, $-\mathrm{CH}(\mathrm{O})-), 129.03-125.22$ (12C, aromatic groups), $63.96(\mathrm{t}$, $2 \mathrm{C},{ }^{1} J_{\mathrm{CH}}=76.6 \mathrm{~Hz}, \mathrm{~N}-\mathrm{CH}_{2}-$, pyrrolidinium ring), $53.52(\mathrm{t}, 1 \mathrm{C}$, ${ }^{1} J_{\mathrm{CH}}=88.7 \mathrm{~Hz}, \mathrm{~N}-\mathrm{CH}_{2}-$ alkyl chain), 47.73 (q, $1 \mathrm{C},{ }^{1} J_{\mathrm{CH}}=68.2$ $\mathrm{Hz}, \mathrm{N}-\mathrm{CH}_{3}$ ), 26.67-18.03 (4C, methylene carbons of the pyrrolidinium ring and methylene carbons of the alkyl chain), 13.41 (q, $1 \mathrm{C},{ }^{1} J_{\mathrm{CH}}=54.4 \mathrm{~Hz},-\mathrm{CH}_{3}$ ) ppm.

${ }^{11} \mathrm{~B}$ NMR (115.5 MHz, $\mathrm{CDCl}_{3}$ ): $11.07 \mathrm{ppm}$.

\subsection{Physicochemical characterisation}

2.3.1 Spectroscopic characterisation. Liquid state NMR spectra of hf-BILs were recorded at $5-10 \mathrm{wt} \%$ in $\mathrm{CDCl}_{3}$ on an Agilent/Varian/Chemagnetics InfinityPlus CMX-360 $(B=8.46 \mathrm{~T})$ spectrometer using a $10 \mathrm{~mm}$ double-resonance probe for liquids tuned to resonance frequencies of ${ }^{1} \mathrm{H}(359.92 \mathrm{MHz}),{ }^{13} \mathrm{C}$ 
(90.51 MHz), or ${ }^{11} \mathrm{~B}(115.48 \mathrm{MHz}) .{ }^{1} \mathrm{H}$ and ${ }^{13} \mathrm{C}$ spectra were internally referenced to $0 \mathrm{ppm}$ resonance peak of TMS and 77.2 resonance peak of $\mathrm{CDCl}_{3}$, respectively. External reference $(0 \mathrm{ppm})$ was used in the ${ }^{11} \mathrm{~B}\left(\mathrm{Et}_{2} \mathrm{O} \cdot \mathrm{BF}_{3}\right)$.

2.3.2 Thermal analysis. Thermal behaviour of hf-BILs was studied using a Thermal Advantage DSC Q1000 (TA Instrument) equipped with a cooling system. Indium was used to calibrate temperature and the enthalpy of phase transitions. The standard/conventional DSC method was used to determine the glass transition temperature $\left(T_{\mathrm{g}}\right)$ and the specific heat capacity of the glass-liquid transition $\left(C_{\mathrm{p}}\right)$ of ILs, as exemplified in Fig. SI-27. $\dagger$ A sample of about $1 \mathrm{mg}$ was accurately weighed and placed into a non-hermetic aluminium pan and crimped. All samples were scanned in a temperature range from 200 to $360 \mathrm{~K}$ using a cool/ heat cycle at a rate of $10 \mathrm{~K} \mathrm{~min}^{-1}$ under continuous nitrogen purge $\left(50 \mathrm{~mL} \mathrm{~min}^{-1}\right)$.

$T_{\mathrm{g}}$ for all these ionic liquids were determined at the onset of the glass-liquid transition using Universal Analysis 2000 V4.3 software (TA Instruments). $C_{\mathrm{p}}$ of the glass-liquid transition is calculated at the central peak transition point. All measurements were performed in duplicate.
The weight loss of hf-BILs as a function of temperature was determined by thermogravimetric analysis (TGA) using a Thermal Advantage TGA Q5000IR (TA Instrument) module. The samples $(5-10 \mathrm{mg})$ were measured in platinum pans $(100 \mu \mathrm{l})$ heated from 298 to $673 \mathrm{~K}$ at a heating rate of $10 \mathrm{~K} \mathrm{~min}^{-1}$ under nitrogen purge. The data was analysed using Universal Analysis 2000 V4.3 software (TA Instruments).

2.3.3 Density. An Anton-Paar DMA 4100M density meter was used to measure densities of BILs in a temperature range from 293 to $353 \mathrm{~K}$. The density meter was calibrated before the measurements using ultra high pure water with a density of $0.998 \mathrm{~g} \mathrm{~cm}^{-3}$ at $293 \mathrm{~K}$.

\subsection{Lubrication performance}

The lubrication performance of hf-BILs was evaluated using a ball-on-disc tribometer. The hf-BILs were mixed with technical grade polyethylene glycol (PEG) at a concentration of $3.0 \mathrm{wt} \%$ using an analytical balance. The mixtures were ultrasonicated for 30 minutes at $353 \mathrm{~K}$ and clear transparent solutions were obtained. $\left[\mathrm{C}_{14} \mathrm{C}_{1}\right.$ Pyrr $][\mathrm{BMB}]$ is not soluble in PEG. PEG was characterised by mass-spectrometry (API 3200 LC/MS System, AB

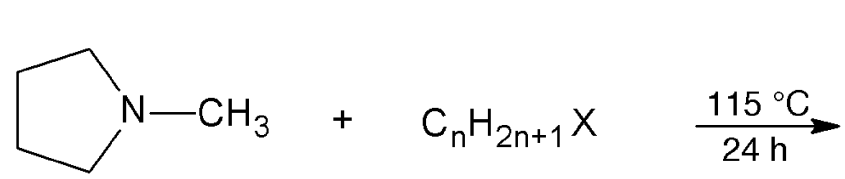<smiles>[X]C[N+]1(C)CCCC1</smiles>

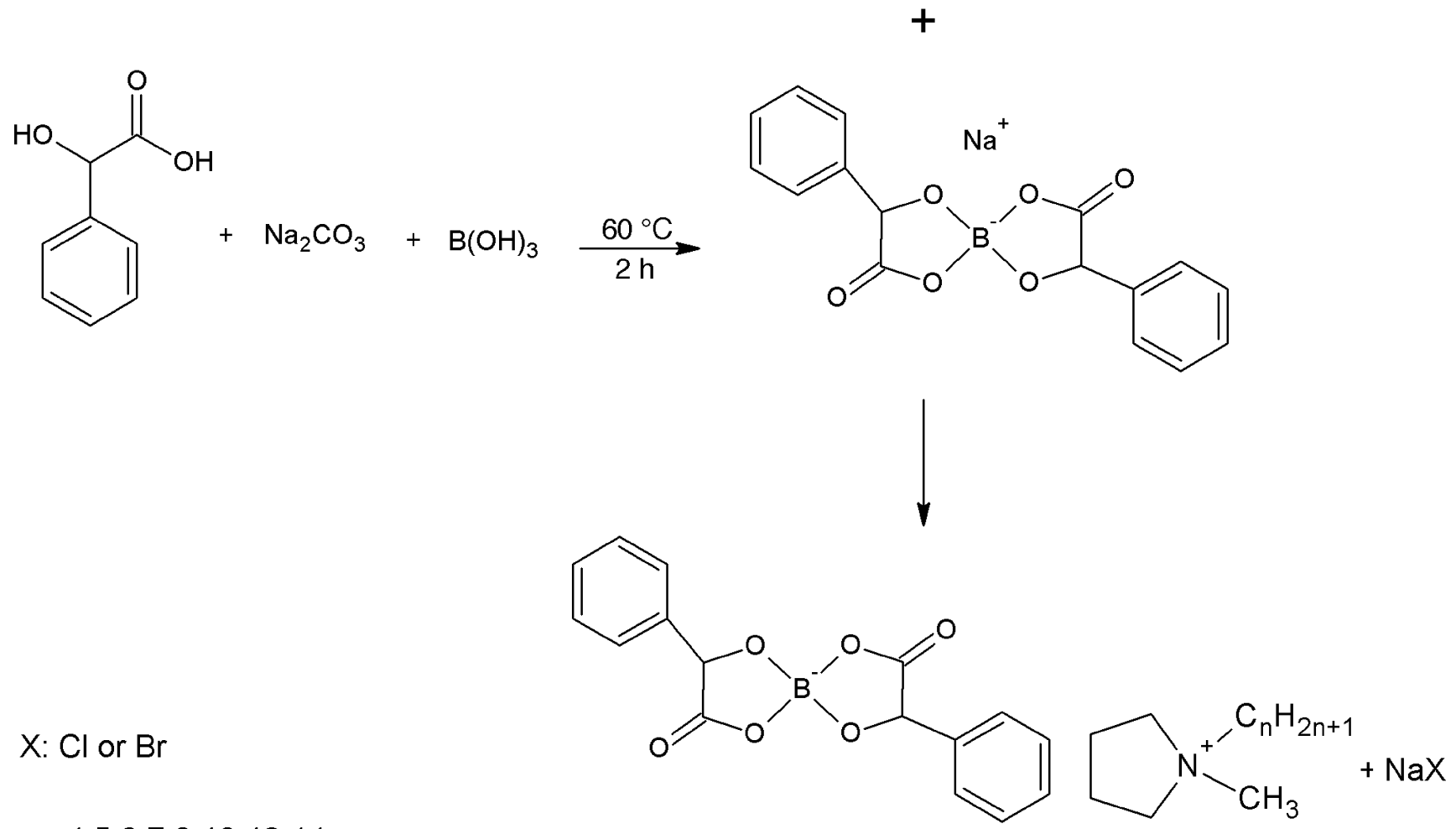

$\mathrm{n}=4,5,6,7,8,10,12,14$

Scheme 1 Synthesis of $N$-alkyl- $N$-methylpyrrolidinium bis(mandelato)borate hf-BILs. 
Sciex, MA, USA). The MS spectrum of PEG demonstrates bimodal distribution of molecular masses centred at 150 and $850 \mathrm{Da}$ (see Fig. SI-25 $\dagger$ ). The PEG used in this study has a viscosity value $134 \mathrm{mPas}$ and a density value $1.030 \mathrm{~g} \mathrm{~cm}^{-3}$ at $313 \mathrm{~K}$.

Friction and wear tests were performed at room temperature under a load of $15 \mathrm{~N}$ and a speed of $0.2 \mathrm{~m} \mathrm{~s}^{-1}$. The test matrix was designed in such a way to investigate the variation of wear as a function of sliding distance. To achieve this, separate runs were performed for 100, 200, 300 and 2000 m sliding distances. It means that the $100 \mathrm{~m}$ runs were repeated four times, the $200 \mathrm{~m}$ runs were repeated three times, etc. The tribo-contact was achieved by pressing the upper stationary 100Cr6 steel ball (diameter $6 \mathrm{~mm}$ ) against the rotating 100Cr6 steel disk (diameter $30 \mathrm{~mm}$ ). The wear coefficients for the steel discs were measured with Surfascan SOMICRONIC profilometer using the following conditions: tip radius $2 \mu \mathrm{m}$; tip angle $90^{\circ}$; cut-off value (ג) $2.5 \mathrm{~mm}$; and filter $50 \%$ Gauss.

\section{Results and discussion}

\subsection{Synthesis and characterisation}

The synthetic procedure for $\left[\mathrm{C}_{4} \mathrm{C}_{1} \mathrm{Pyrr}\right][\mathrm{BMB}]$ is described in detail in the Experimental section. As illustrated in Scheme 1, the synthesis of hf-BILs started with a $N$-methylpyrrolidinium and the corresponding alkyl halides in a $1: 1$ molar ratio. After refluxing for 24 hours at $388 \mathrm{~K}$, the reaction mixture was cooled down to room temperature and a solid product of $N$-butyl- $N$ methylpyrrolidinium chloride was obtained.

In the second step, the sodium salt of chelated orthoborate was obtained by mixing mandelic acid, boric acid and sodium carbonate in a $2: 1: 1$ molar ratio dissolved in distilled water. The reaction mixture was cooled down to room temperature after heating for 2 hours at about $333 \mathrm{~K}$. Chloride salt of $N$-butyl$\mathrm{N}$-methylpyrrolidinium prepared in the first step was added to the aqueous solution of chelated orthoborate salt. The immediately formed reaction product, an organic layer, was extracted with dichloromethane (DCM) and washed three times with distilled water to remove any traces of the by-product, sodium halide. DCM and residual water were rotary evaporated from the final products, dialkylpyrrolidinium bis(mandelato)borates ILs. Traces of water and DCM were then removed under vacuum $\left(<10^{-3}\right.$ mbar) during 5 hours at $343 \mathrm{~K}$. Water content in hf-BILs was found to be within 0.035-0.109 wt\% (see Table SI-1 in ESI $\dagger$ ). Sodium content in hf-BILs was found to be within 0.0068$0.0254 \mathrm{wt} \%$ while the halogen content was found to be within 0.0244-1.0710 wt\% (see Table SI-1 in ESI $\dagger$ ). In the formulated PEG based lubricants the concentration of these elements is 33 times lower.

The chemical structure and purity of synthesised hf-BILs were characterised by multinuclear $\left({ }^{1} \mathrm{H},{ }^{13} \mathrm{C}\right.$, and $\left.{ }^{11} \mathrm{~B}\right)$ NMR spectroscopy and the "CHN" elemental analysis. The data obtained confirmed the structure and purity of all synthesised ILs.

\subsection{Thermal analysis}

DSC curves of selected pyrrolidinium bis(mandelato)borate hfBILs are shown in Fig. 1. The glass transition temperatures $\left(T_{\mathrm{g}}\right)$

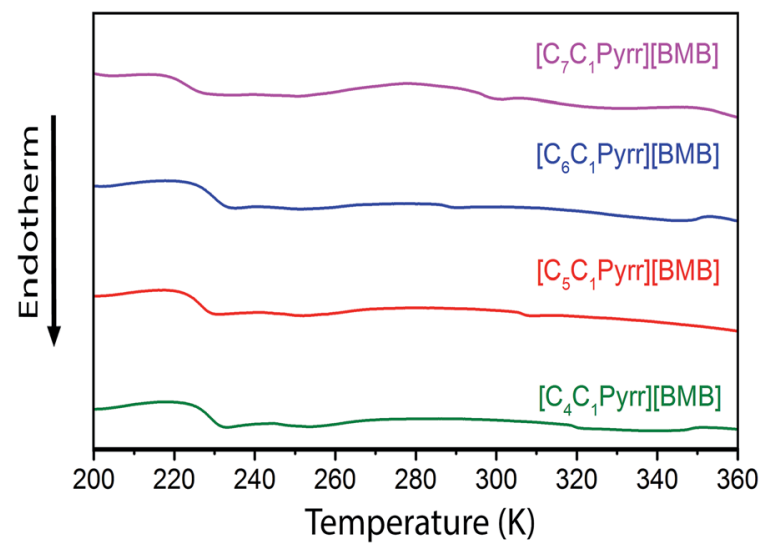

Fig. 1 DSC thermograms of selected $N$-alkyl- $N$-methylpyrrolidinium bis(mandelato)borate hf-BILs.

Table 1 Thermal properties of $N$-alkyl- $N$-methylpyrrolidinium bis(mandelato)borate hf-BILs

\begin{tabular}{lll}
\hline hf-BIL & $T_{\mathrm{g}}(\mathrm{K})$ & $C_{\mathrm{p}}\left(\mathrm{J} \mathrm{kg}^{-1} \mathrm{~K}^{-1}\right)$ \\
\hline$\left[\mathrm{C}_{2} \mathrm{C}_{1}\right.$ Pyrr $][\mathrm{BMB}]$ & $271^{a}$ & $412.2^{a}$ \\
{$\left[\mathrm{C}_{4} \mathrm{C}_{1}\right.$ Pyrr $][\mathrm{BMB}]$} & $225.6 \pm 0.1$ & $412.2 \pm 0.3$ \\
{$\left[\mathrm{C}_{5} \mathrm{C}_{1}\right.$ Pyrr][BMB] } & $223.3 \pm 0.5$ & $442.6 \pm 0.7$ \\
{$\left[\mathrm{C}_{6} \mathrm{C}_{1}\right.$ Pyrr][BMB] } & $225.8 \pm 0.5$ & $519.6 \pm 0.5$ \\
{$\left[\mathrm{C}_{7} \mathrm{C}_{1}\right.$ Pyrr][BMB] } & $218.2 \pm 0.3$ & $302.7 \pm 0.6$ \\
{$\left[\mathrm{C}_{8} \mathrm{C}_{1}\right.$ Pyrr][BMB] } & $225.6 \pm 0.5$ & $288.8 \pm 0.8$ \\
{$\left[\mathrm{C}_{10} \mathrm{C}_{1}\right.$ Pyrr] $][\mathrm{BMB}]$} & $235.6 \pm 0.6$ & $419.5 \pm 0.7$ \\
{$\left[\mathrm{C}_{12} \mathrm{C}_{1}\right.$ Pyrr $][\mathrm{BMB}]$} & $235.5 \pm 0.4$ & $266.5 \pm 0.3$ \\
{$\left[\mathrm{C}_{14} \mathrm{C}_{1}\right.$ Pyrr][BMB] } & $240.9 \pm 0.8$ & $462.4 \pm 0.5$
\end{tabular}

${ }^{a}$ Ref. 21.

and specific heat capacities of the glass-liquids transition $\left(C_{\mathrm{p}}\right)$ are tabulated in Table 1 . All the reported pyrrolidinium bis(mandelato)borate hf-BILs are viscous liquids at room temperature with glass transition temperatures between 218 and $241 \mathrm{~K}$.

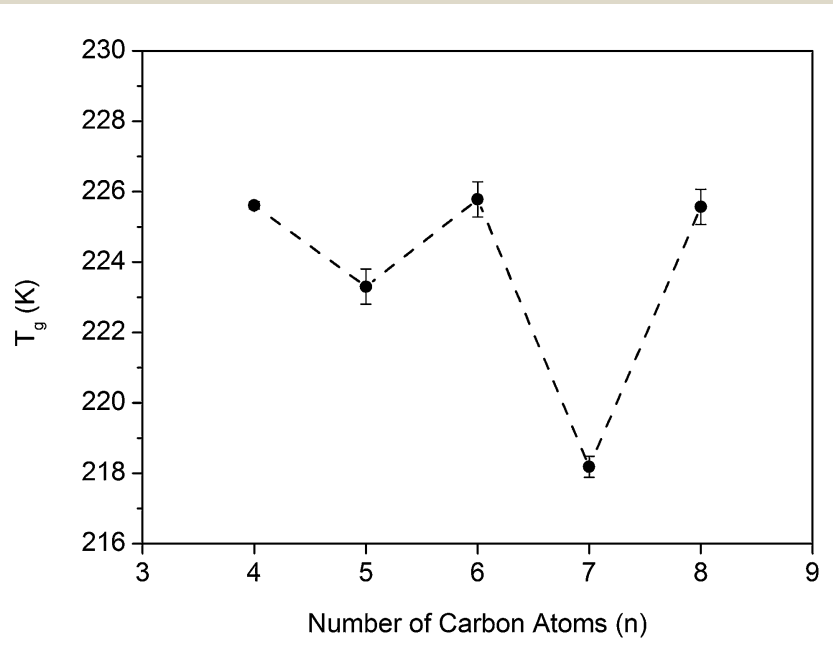

Fig. 2 "Odd-even" effect of the longest alkyl chain length in $\mathrm{N}$-alkyl$N$-methylpyrrolidinium bis(mandelato)borate on the glass transition temperature $\left(T_{\mathrm{g}}\right)$. 


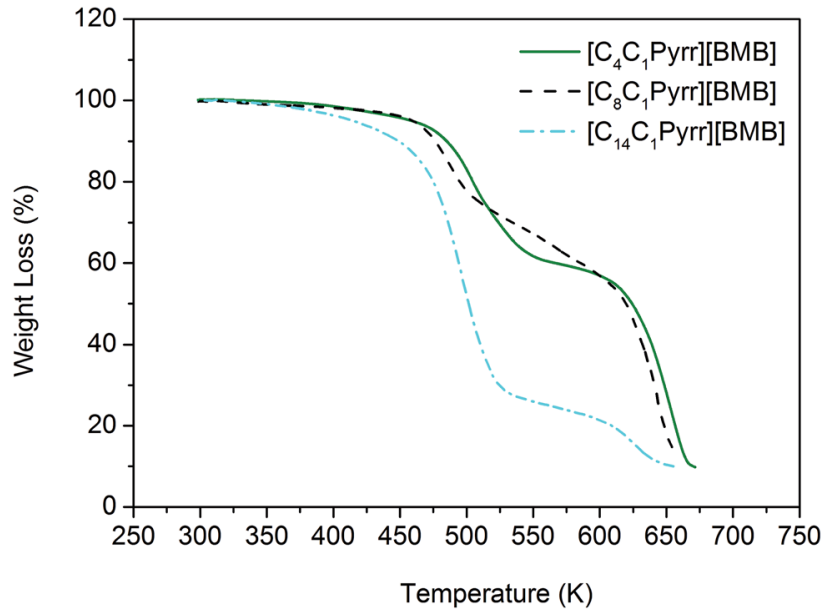

Fig. 3 Thermogravimetric analysis of $N$-alkyl- $N$-methylpyrrolidinium bis(mandelato)borate hf-BILs.

The DSC curves show no evidence of melting points. It was found that $T_{\mathrm{g}}$ and $C_{\mathrm{p}}$ of the hf-BILs are significantly affected by the length of one of the alkyl chains attached to the pyrrolidinium ring. A comparative analysis of the thermal behaviour reveals that $\left[\mathrm{C}_{7} \mathrm{C}_{1}\right.$ Pyrr $][\mathrm{BMB}]$ has the lowest $T_{\mathrm{g}}(218 \mathrm{~K})$, while $\left[\mathrm{C}_{14} \mathrm{C}_{1} \mathrm{Pyrr}\right][\mathrm{BMB}]$ shows the highest $T_{\mathrm{g}}(241 \mathrm{~K})$.

$T_{\mathrm{g}}$ changes irregularly with the number of carbon atoms $n=4-14$ in the longest alkyl chain (see Table 1). $T_{\mathrm{g}}$ increases in the following order $\left[\mathrm{C}_{7} \mathrm{C}_{1}\right.$ Pyrr $][\mathrm{BMB}]<\left[\mathrm{C}_{5} \mathrm{C}_{1}\right.$ Pyrr $][\mathrm{BMB}]<$ $\left[\mathrm{C}_{8} \mathrm{C} 1\right.$ Pyrr $][\mathrm{BMB}]<\left[\mathrm{C}_{4} \mathrm{C}_{1}\right.$ Pyrr $][\mathrm{BMB}]<\left[\mathrm{C}_{6} \mathrm{C}_{1}\right.$ Pyrr $][\mathrm{BMB}]<$ $\left[\mathrm{C}_{12} \mathrm{C}_{1}\right.$ Pyrr $][\mathrm{BMB}]<\left[\mathrm{C}_{10} \mathrm{C}_{1}\right.$ Pyrr $][\mathrm{BMB}]<\left[\mathrm{C}_{14} \mathrm{C}_{1}\right.$ Pyrr $][\mathrm{BMB}] . C_{\mathrm{p}}$ changes irregularly with the number of carbon atoms $n=4-14$, increasing in the following order $\left[\mathrm{C}_{6} \mathrm{C}_{1}\right.$ Pyrr $][\mathrm{BMB}]<\left[\mathrm{C}_{14} \mathrm{C}_{1}\right.$ Pyrr $]$ $[\mathrm{BMB}]<\left[\mathrm{C}_{5} \mathrm{C}_{1}\right.$ Pyrr $][\mathrm{BMB}]<\left[\mathrm{C}_{10} \mathrm{C}_{1} \mathrm{Pyrr}\right][\mathrm{BMB}]<\left[\mathrm{C}_{4} \mathrm{C}_{1}\right.$ Pyrr $][\mathrm{BMB}]$ $<\left[\mathrm{C}_{7} \mathrm{C}_{1}\right.$ Pyrr $][\mathrm{BMB}]<\left[\mathrm{C}_{8} \mathrm{C}_{1}\right.$ Pyrr $][\mathrm{BMB}]<\left[\mathrm{C}_{12} \mathrm{C}_{1}\right.$ Pyrr $][\mathrm{BMB}]$.

The glass transition temperatures of these hf-BILs if compared exhibit a distinct "odd-even" effect (see Fig. 2). Higher $T_{\mathrm{g}}$ were detected for ILs with even number of carbons in

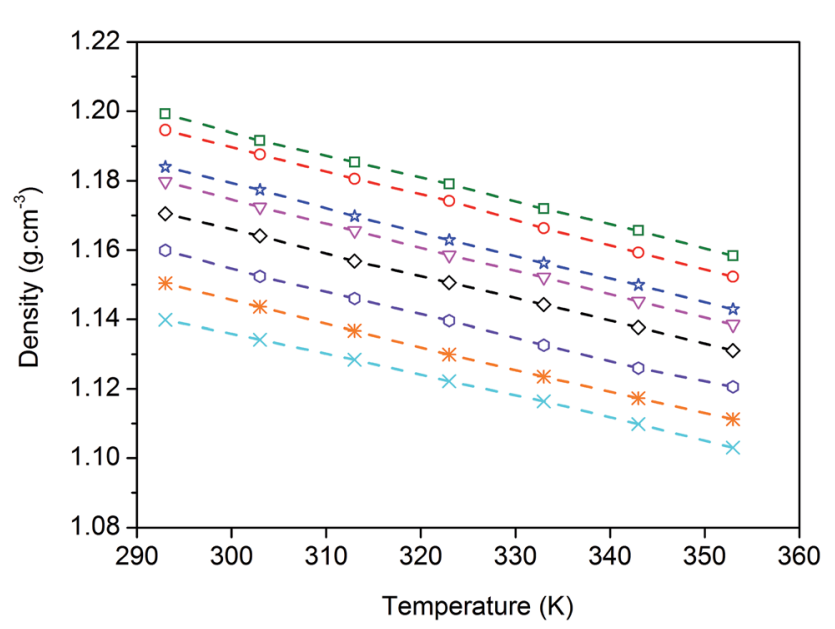

Fig. 4 Density of $N$-alkyl- $N$-methylpyrrolidinium bis(mandelato)borate hf-BILs as a function of temperature. From top to bottom: $\left[C_{4} C_{1}\right.$ Pyrr][BMB], [C ${ }_{5} C_{1}$ Pyrr][BMB], [C $C_{6} C_{1}$ Pyrr] [BMB], [C $C_{7} C_{1}$ Pyrr] [BMB], $\left[C_{8} C_{1}\right.$ Pyrr][BMB], $\left[C_{10} C_{1}\right.$ Pyrr] [BMB], $\left[C_{12} C_{1}\right.$ Pyrr][BMB] and $\left[C_{14} C_{1}\right.$ Pyrr] [BMB]. the longest alkyl chain. A similar "odd-even” effect has been reported earlier for melting points, solid-solid phase transition, entropy and enthalpy of vaporisation, viscosity and density for other types of ILs. ${ }^{\mathbf{1 0 , 2 5}}$ In general, thermal behaviour of ILs is affected by the structure and nature of both cations and anions, i.e. by intermolecular forces, molecular symmetry and conformational degrees of freedom of the ions. ${ }^{\mathbf{4 , 2 6 , 2 7}}$

The thermal stabilities of $\left[\mathrm{C}_{4} \mathrm{C}_{1} \mathrm{Pyrr}\right][\mathrm{BMB}],\left[\mathrm{C}_{8} \mathrm{C}_{1} \mathrm{Pyrr}\right][\mathrm{BMB}]$ and $\left[\mathrm{C}_{14} \mathrm{C}_{1} \mathrm{Pyrr}\right][\mathrm{BMB}]$ were assessed by the thermogravimetric analysis. Fig. 3 reveals that $\left[\mathrm{C}_{14} \mathrm{C}_{1} \mathrm{Pyrr}\right][\mathrm{BMB}]$ is less thermally stable compared to $\left[\mathrm{C}_{4} \mathrm{C}_{1} \mathrm{Pyrr}\right][\mathrm{BMB}]$ and $\left[\mathrm{C}_{8} \mathrm{C}_{1} \mathrm{Pyrr}\right][\mathrm{BMB}]$. Decomposition of $\left[\mathrm{C}_{14} \mathrm{C}_{1}\right.$ Pyrr] $[\mathrm{BMB}]$ starts just above $370 \mathrm{~K}$, while the onset of abrupt decomposition is above $c a .485 \mathrm{~K}$. In the case of $\left[\mathrm{C}_{4} \mathrm{C}_{1} \mathrm{Pyrr}\right][\mathrm{BMB}]$, weight loss is observed around $480 \mathrm{~K}$. It decomposes through two steps; the onset temperature of the first step of decomposition is $c a .480 \mathrm{~K}$ and the onset of the second step is $c a .630 \mathrm{~K}$. The behaviour of $\left[\mathrm{C}_{8} \mathrm{C}_{1} \mathrm{Pyrr}\right][\mathrm{BMB}]$ is similar to the behaviour of $\left[\mathrm{C}_{4} \mathrm{C}_{1} \mathrm{Pyrr}\right][\mathrm{BMB}]$. No weight loss is observed until ca. $480 \mathrm{~K}$. Stepwise decomposition behaviour is revealed at onset temperatures of $c a .480$ and $620 \mathrm{~K}$.

An IL containing bis(mandelato)borate $\left([\mathrm{BMB}]^{-}\right)$with trihexyltetradecylphosphonium cation is more thermally stable than $N$-alkyl- $N$-methylpyrrolidinium bis(mandelato)borate ILs. ${ }^{3}$

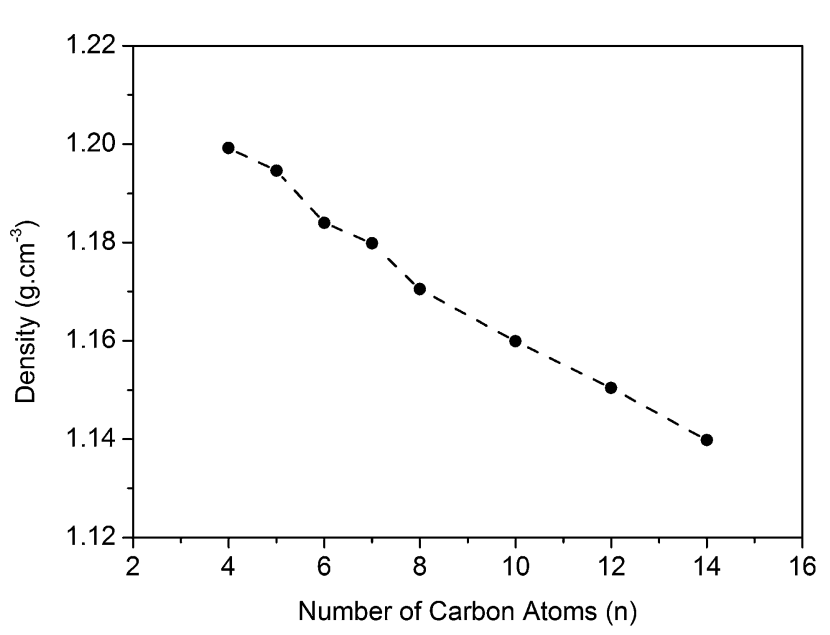

Fig. 5 Effect of the alkyl chain length of $N$-alkyl- $N$-methylpyrrolidinium bis(mandelato)borate on densities of BILs at $293 \mathrm{~K}$.

Table 2 Densities of $N$-alkyl- $N$-methylpyrrolidinium bis(mandelato) borate hf-BILs

\begin{tabular}{llll}
\hline Density equation: $d=b-a T, \mathrm{~g} \mathrm{~cm}^{-3}$ & & \\
\hline hf-BIL & $a \times 10^{-4}$ & $b$ & $R^{2}$ \\
\hline$\left[\mathrm{C}_{4} \mathrm{C}_{1}\right.$ Pyrr][BMB] & 7.0 & 1.3958 & 0.9994 \\
{$\left[\mathrm{C}_{5} \mathrm{C}_{1}\right.$ Pyrr][BMB] } & 7.0 & 1.4017 & 0.9996 \\
{$\left[\mathrm{C}_{6} \mathrm{C}_{1}\right.$ Pyrr][BMB] } & 7.0 & 1.3847 & 0.9995 \\
{$\left[\mathrm{C}_{7} \mathrm{C}_{1}\right.$ Pyrr] $][\mathrm{BMB}]$} & 7.0 & 1.3801 & 0.9997 \\
{$\left[\mathrm{C}_{8} \mathrm{C}_{1}\right.$ Pyrr $][\mathrm{BMB}]$} & 7.0 & 1.3624 & 0.9997 \\
{$\left[\mathrm{C}_{10} \mathrm{C}_{1}\right.$ Pyrr $][\mathrm{BMB}]$} & 7.0 & 1.3520 & 0.9989 \\
{$\left[\mathrm{C}_{12} \mathrm{C}_{1}\right.$ Pyrr $][\mathrm{BMB}]$} & 7.0 & 1.3419 & 0.9994 \\
{$\left[\mathrm{C}_{14} \mathrm{C}_{1}\right.$ Pyrr $][\mathrm{BMB}]$} & 6.0 & 1.3195 & 0.9989
\end{tabular}


This demonstrates the important role of cations for thermal stability of orthoborate based ILs.

\subsection{Density}

Fig. 4 shows a linear decrease in densities of the hf-BILs with temperature. Density also reduces gradually if the length of the alkyl chain connected to the pyrrolidinium ring is increased from 4 to 14 (see Fig. 5).

Density of the hf-BILs decreased in the following order: $\left[\mathrm{C}_{4} \mathrm{C}_{1}\right.$ Pyrr $][\mathrm{BMB}]>\left[\mathrm{C}_{5} \mathrm{C}_{1}\right.$ Pyrr $][\mathrm{BMB}]>\left[\mathrm{C}_{6} \mathrm{C}_{1}\right.$ Pyrr $][\mathrm{BMB}]>$ $\left[\mathrm{C}_{7} \mathrm{C}_{1} \mathrm{Pyrr}\right][\mathrm{BMB}]>\left[\mathrm{C}_{8} \mathrm{C}_{1} \mathrm{Pyrr}\right][\mathrm{BMB}]>\left[\mathrm{C}_{10} \mathrm{C}_{1} \mathrm{Pyrr}\right][\mathrm{BMB}]>$ $\left[\mathrm{C}_{12} \mathrm{C}_{1}\right.$ Pyrr $][\mathrm{BMB}]>\left[\mathrm{C}_{14} \mathrm{C}_{1}\right.$ Pyrr $][\mathrm{BMB}]$. Interestingly, the "oddeven" effect for densities of these hf-BILs is very small (compare data for $n=4-8$ in Fig. 5).

The decrease in densities of the hf-BILs with an increase in temperature from 293 to $353 \mathrm{~K}$ follows a linear regression (see Table 2). This behaviour can be explained by a reduction in van

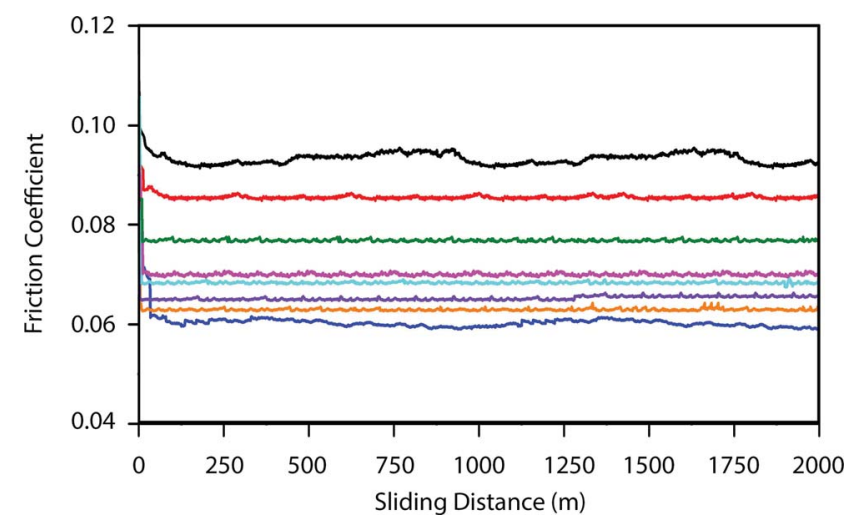

Fig. 6 Variation of the friction coefficient with the sliding distance in the steel ball on steel disk contact lubricated by 5 W40 oil, neat PEG or PEG with 3 wt\% $\left[C_{n} C_{1}\right.$ Pyrr] $[B M B]$. Room temperature (298 K), $15 \mathrm{~N}$ load, $0.2 \mathrm{~m} \mathrm{~s}^{-1}$ sliding speed. Friction curves from top to bottom: 5W40, neat PEG, $\left[C_{12} C_{1}\right.$ Pyrr $][B M B] / P E G, \quad\left[C_{8} C_{1}\right.$ Pyrr $][B M B] / P E G$, $\left[C_{7} C_{1}\right.$ Pyrr] [BMB]/PEG, $\left[C_{6} C_{1}\right.$ Pyrr][BMB]/PEG, $\left[C_{5} C_{1}\right.$ Pyrr][BMB]/PEG and $\left[\mathrm{C}_{4} \mathrm{C}_{1} \mathrm{Pyrr}\right][\mathrm{BMB}] / \mathrm{PEG}$.

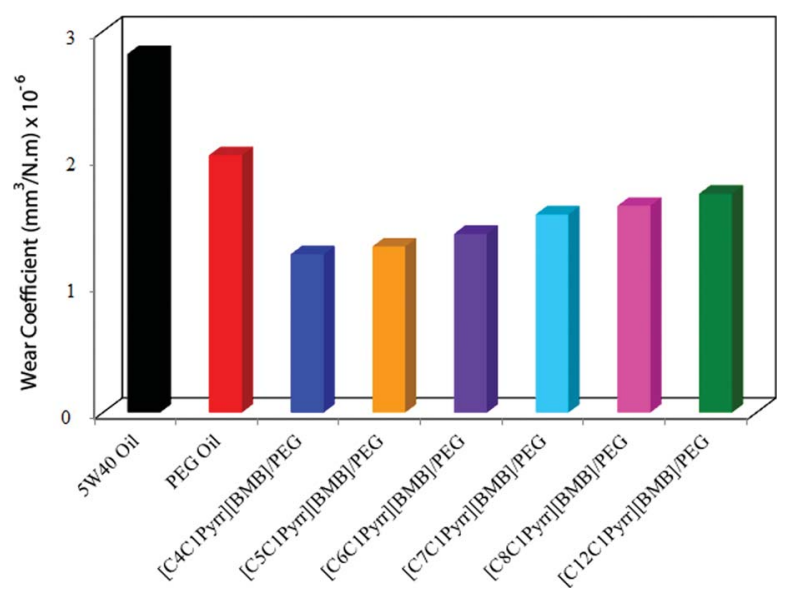

Fig. 7 Wear coefficients for the discs lubricated by 5 W40 oil, neat PEG or PEG containing $3 \mathrm{wt} \%$ of a hf-BIL. Tests were performed at room temperature, steel-steel contacts, $15 \mathrm{~N}$ load, $0.2 \mathrm{~m} \mathrm{~s}^{-1}$ sliding speed.

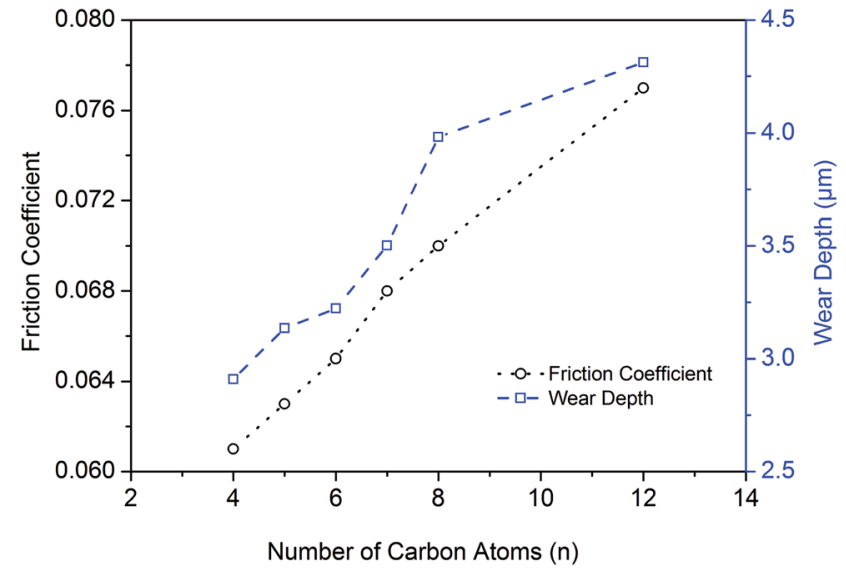

Fig. 8 The effect of the alkyl chain length of $N$-alkyl- $N$-methylpyrrolidinium bis(mandelato)borate on the wear depth and friction coefficient. The tests were performed at room temperature with $3 \mathrm{wt} \%$ of a hf-BIL in PEG at $15 \mathrm{~N}$ load and sliding speed of $0.2 \mathrm{~m} \mathrm{~s}^{-1}$ for $2000 \mathrm{~m}$ sliding distance.

der Waals interactions leading to a less efficient packing of ions. $^{3}$ Parameters characterising density of these hf-BILs as a function of temperature are tabulated in Table 2. The linear reduction in density with temperature is typical for many ILs. ${ }^{3,28}$

\subsection{Lubrication performance}

Fig. 6 shows friction reducing performance of the $\left[\mathrm{C}_{n} \mathrm{C}_{1} \mathrm{Pyrr}\right]$ [BMB] hf-BILs as $3 \mathrm{wt} \%$ additives in PEG in comparison with the neat PEG and 5W40 oil in the steel-steel contacts. The data reveals that $\left[\mathrm{C}_{n} \mathrm{C}_{1}\right.$ Pyrr $][\mathrm{BMB}] / \mathrm{PEG}$ mixtures provide significantly lower friction than the neat PEG and 5W40 oil. Friction coefficient is also more stable compared to 5W40 oil. The "odd-even" effect of the alkyl chain length in the cation is not visible in the friction traces. But there is a clear influence of the alkyl chain length on the friction level.

The effect of sliding distance on the wear rate was studied by performing the tests at different sliding distances: 100, 200, 300 and $2000 \mathrm{~m}$. The friction curves and wear data for 100, 200 and 300 sliding distances are shown in Fig. SI-28 to SI-31. $\dagger$ Initially all compounds showed similar wear rates but as the sliding distance increased the wear rates for the neat PEG and 5W40 oil significantly increased. Adding a hf-BIL to PEG considerably reduced the wear rate increase indicating formation of stable tribolayers on the contacting surfaces. The wear coefficients, presented in Fig. 7, were calculated for the wear scars on the discs for the sliding distance of $2000 \mathrm{~m}$. The discs lubricated with 5W40 oil or neat PEG oil had the largest wear. The wear coefficients for the discs lubricated with PEG containing $3 \mathrm{wt} \%$ of $\left[\mathrm{C}_{n} \mathrm{C}_{1}\right.$ Pyrr $][\mathrm{BMB}]$ are considerably lower.

A comparative analysis of the friction and wear data reveals that pyrrolidinium cations with the shorter alkyl chains provide better antiwear and friction reducing performance compared to cations with the longer alkyl chains (see Fig. 7 and 8). This result can be explained by the higher mobility of hf-BILs with the shorter alkyl chains in the base fluid. As a result, availability of hf-BIL at the rubbed surfaces is higher. 
Mechanism of lubrication by ILs can be thought as a combination of the following processes: (i) ILs tend to adsorb on rubbed surfaces due to their ionic nature. This process is encouraged by the electron deficiency of the interacting steel surfaces. ${ }^{13,17}$ Adsorption leads to formation of easy to shear overlayers of anions and cations. (ii) ILs can break down and chemically react with the rubbed surfaces forming protective overlayers usually called "tribofilms".

As noted above, tribological performance of an IL in the base fluid is affected by its interactions with the base fluid. Two categories of interactions can be distinguished: (i) interactions between ions in IL and (ii) interactions between the ions of IL and the molecules of the base oil. In general, less interaction between an IL and the base fluid means higher availability of the IL additive at the contacting surfaces, and thus better friction and wear performance. ${ }^{\mathbf{1 3 , 2 9}}$

\section{Conclusion}

Halogen-free boron-based ILs, namely pyrrolidinium bis(mandelato)borates with different alkyl chain lengths in the pyrrolidinium cation, were successfully synthesised and characterised. The synthesised ILs are liquids at room temperature with glass transition temperatures ranging from 218 to $241 \mathrm{~K}$. The length of the longest alkyl chain bonded to the nitrogen atom of the pyrrolidinium cation has a significant influence on the physicochemical properties of this class of hf-BILs. Glass transition temperatures varied as a function of the number of carbon atoms in the longest alkyl chain in pyrrolidinium cations. An "odd-even" effect on $T_{\mathrm{g}}$ of these hf-BILs was discovered. Lower $T_{\mathrm{g}}$ values for $n=5$ and 7 and higher $T_{\mathrm{g}}$ values for $n=4,6,8,10$, 12 and 14 were observed. Density of hf-BILs decreases linearly with the increasing temperature in the temperature range typical for lubrication industry. $\left[\mathrm{C}_{n} \mathrm{C}_{1} \mathrm{Pyrr}\right][\mathrm{BMB}] \mathrm{hf}-\mathrm{BILS}$ ( $n=4-8$ and 12 ) if added to PEG at $3 \mathrm{wt} \%$ significantly reduce friction and wear in the steel-steel contacts in comparison with the neat PEG and $5 \mathrm{~W} 40$ oil. The best performance is provided by the $\left[\mathrm{C}_{4} \mathrm{C}_{1}\right.$ Pyrr $][\mathrm{BMB}]$ hf-BIL.

\section{Acknowledgements}

The Knut and Alice Wallenberg Foundation and the Swedish Research Council are gratefully acknowledged for supporting this work. The Foundation in memory of J. C. and Seth M. Kempe is gratefully acknowledged for the grants for NMR equipment at LUT, stipends for MT and FUS and chemicals. Swedish Research School in Tribology is acknowledged for financing MT's research visits to Ghent University, Belgium. We thank Prof. Velaga and Dr Shimpi for assistance with DSC and TGA experiments at LUT.

\section{References}

1 F. U. Shah, S. Glavatskih and O. N. Antzutkin, Tribol. Lett., 2013, 51, 281-301.

2 C. Ye, W. Liu, Y. Chen and L. Yu, Chem. Commun., 2001, 21, 2244-2245.
3 F. U. Shah, S. Glavatskih, D. R. MacFarlane, A. Somers, M. Forsyth and O. N. Antzutkin, Phys. Chem. Chem. Phys., 2011, 13, 12865-12873.

4 J. Ranke, S. Stolte, R. Stormann, J. Arning and B. Jastorff, Chem. Rev., 2007, 107, 2183-2206.

5 R. P. Swatloski, J. D. Holbrey and R. D. Rogers, Green Chem., 2003, 5, 361-363.

6 A. E. Visser, R. P. Swatloski, W. M. Reichert, R. Mayton, S. Sheff, A. Wierzbicki, J. H. Davis Jr and R. D. Rogers, Chem. Commun., 2001, 1, 135-136.

7 T. Welton, Coord. Chem. Rev., 2004, 248, 2459-2477.

8 M. Antonietti, D. Kuang, B. Smarsly and Y. Zhou, Angew. Chem., Int. Ed., 2004, 43, 4988-4992.

9 X. Sun, H. Luo and S. Dai, Chem. Rev., 2011, 112, 2100-2128. 10 W. Zheng, A. Mohammed, L. G. Hines Jr, D. Xiao, O. J. Martinez, R. A. Bartsch, S. L. Simon, O. Russina, A. Triolo and E. L. Quitevis, J. Phys. Chem. B, 2011, 115, 6572-6584.

11 X. Liu, F. Zhou, Y. Liang and W. Liu, Wear, 2006, 261, 11741179.

12 H. Arora and P. Cann, Tribol. Int., 2010, 43, 1908-1916.

13 A. E. Somers, B. Khemchandani, P. C. Howlett, J. Sun, D. R. MacFarlane and M. Forsyth, ACS Appl. Mater. Interfaces, 2013, 5, 11544-11553.

14 S. Fang, Z. Zhang, Y. Jin, L. Yang, S. Hirano, K. Tachibana and S. Katayama, J. Power Sources, 2011, 196, 5637-5644.

15 T. Welton, Chem. Rev., 1999, 99, 2071-2084.

16 A. Berthod, M. Ruiz-Angel and S. Carda-Broch, J. Chromatogr. A, 2008, 1184, 6-18.

17 A. E. Somers, P. C. Howlett, D. R. MacFarlane and M. Forsyth, Lubricants, 2013, 1, 3-21.

18 T. Fukushima and T. Aida, Chem.-Eur. J., 2007, 13, 50485058.

19 R. L. Gardas, H. F. Costa, M. G. Freire, P. J. Carvalho, I. M. Marrucho, I. M. Fonseca, A. G. Ferreira and J. A. Coutinho, J. Chem. Eng. Data, 2008, 53, 805-811.

20 P. Wasserscheid, A. Bosmann and R. V. Hal, US Patent, 7,863,458, 2011.

21 F. U. Shah, S. Glavatskih, P. M. Dean, D. R. MacFarlane, M. Forsyth and O. N. Antzutkin, J. Mater. Chem., 2012, 22, 6928-6938.

22 M. Yang, F. Xu, Q. Liu, P. Yan, X. Liu, C. Wang and U. WelzBiermann, Dalton Trans., 2010, 39, 10571-10573.

23 S. Yu, S. Lindeman and C. D. Tran, J. Org. Chem., 2008, 73, 2576-2591.

24 D. R. MacFarlane, J. Golding, S. Forsyth, M. Forsyth and G. B. Deacon, Chem. Commun., 2001, 273, 1430-1431.

25 M. A. Rocha, J. A. Coutinho and L. M. Santos, J. Phys. Chem. $B, 2012,116,10922-10927$.

26 P. Wasserscheid and W. Keim, Angew. Chem., 2000, 39, 37723789.

27 M. Nieuwenhuyzen, K. R. Seddon, F. Teixidor, A. V. Puga and C. Vinas, Inorg. Chem., 2009, 48, 889-901.

28 C. P. Fredlake, J. M. Crosthwaite, D. G. Hert, S. N. Aki and J. F. Brennecke, J. Chem. Eng. Data, 2004, 49, 954-964.

29 R. Gusain, R. Singh, K. Sivakumar and O. P. Khatri, RSC Adv., 2014, 4, 1293-1301. 